\title{
Physical and Psychological Violence in Dating with Sleep Duration of Adolescents in Bantul Regency
}

\author{
Suci Musvita Ayu*, Liena Sofiana, Dina Ayu Martantita, and Erni Gustina \\ Faculty of Public Health, Universitas Ahmad Dahlan, Indonesia \\ *corresponding author, email: suci.ayu@ikm.uad.ac.id;
}

\section{ARTICLE INFO}

\section{Article history}

Received 08/03/2021

Revised 09/23/2021

Accepted 10/01/2021

Keywords

Physical violence

Psychological violence

Sleep duration

Adolesence

\section{ABSTRACT}

Background: The trend of juvenile delinquency, especially Dating Violence (DV) is still very high. According to the Annual Records (Catahu), there were 2,073 cases in 2018. The Special Region of Yogyakarta ranked sixth as region with the highest DV cases in Indonesia, reaching 980 cases in 2018. In Bantul Regency, 80 cases were reported in 2018. Dating violence can have negative impact on the physical and psychological wellbeing of adolescents. Physical violence can lead to bruises and fractures while psychological violence affects the victims in the form of depression, stress, anxiety and sleep disturbances. This study aims to analyze the relationship between physical and psychological violence in dating with sleep duration of adolescents. Method: This research used quantitative research method with a cross sectional approach. Data were analyzed using chi square. The sample consisted of 314 high school students (15-19 years old) who were recruited using purposive sampling technique. Only subjects who have dated or are currently dating were included in this study. Results: The results showed that there was a relationship between physical violence in dating and sleep duration $(\mathrm{PR}=1,165 ; 95 \% \mathrm{Cl}=1,050-1,293$; $\mathrm{p}<0.05)$. However, there was no relationship between psychological violence in dating and sleep duration $(P R=1,068$; $95 \% \mathrm{Cl}=0,957-1,192 ; p>0.05)$. Conclusion: The results suggest that there is a relationship between physical violence in dating and sleep duration. Teenagers are advised to take advantage of the PIK-R program at school or visit counseling teachers that can help them solving their problems.

This is an open access article under the CC-BY-SA license.

\section{Introduction}

Violence in dating (DV) is a phenomenon that often happened in the society. Nearly a third of women in the world who are in a relationship have experienced physical or sexual violence from their partner [1]. Teenagers can experience DV because their mental and emotional conditions are still developing. Thus, some are not able to control themselves and act violently without thinking. This makes teenagers vulnerable and creates problems in courtship that seem complicated and are difficult to deal with. As most teenagers are inexperienced, they are prone to commit violence acts. Such circumstances make dating in adolescents very vulnerable to violence [2]. Violence has a direct impact on women's health. In some cases, it can have severe impacts on the victim both in physical and mental health. Some effects can last for a long time even after the violence stops [3]. Violence from a partner is one of the most painful and traumatic experiences as it destroys trust and security [4].

Violence during dating can be categorized into physical violence, psychological abuse, and sexual coercion [5]. Physical violence refers to using or attempting to use physical abusive behavior such as pushing, hitting, slapping, and throwing objects. Psychological violence can be 
in the form of humiliation, yelling, and giving certain names or nicknames that are degrading. Sexual violence includes coercing partners using verbal or physical violence to engage in a sexual activity without their consent $[6,7]$.

Some studies reported that DV can cause negative impacts both in the form of physical and psychological impacts. Physical impacts include wounds such as cuts, bruises, and fractures while psychological impacts can lead to anxiety, fear, trauma, low self-esteem, stress, depression, and even death. In some cases, DV works like a cycle, making it difficult to stop unless the victim dares to get out of it [8].

Several studies reveal that DV can negatively impact the victims' health. These can be in the form of sleep disorders, eating disorders, weakened immune system, and low energy. These impacts can lead to a more serious impact, namely depression [9]. Sleep disorders do not only negatively affect adolescents' health but also disrupt their concentration level, thus disrupting their learning activity at school [10].

According to a report, $42.7 \%$ unmarried women have experienced relationship violence, and from 10,847 violence perpetrators, 2,090 perpetrators were girlfriends/friends [11]. The number of DV cases are still high in Indonesia. In 2017, there were 1,873 cases of violence. This number rose to 2073 in 2018 . The number of violence in dating are consistently increasing. A report revealed that the number of DV reached 703 cases while 216 DV cases were recorded in district court. The age of DV victims ranges from 13-18 years old while the perpetrators' age ranges from 19-24 years old [12].

In 2018, the Special Region of Yogyakarta ranked sixth as the region with the highest case of violence against women with 980 cases. In 2015, there were 90 cases of violence against women in Bantul Regency. This number increased to 94 cases in 2016 and 131 cases in 2017 [12]. In 2017 and 2018, there were 74 cases and 80 cases of dating violence respectively in Bantul Regency [13]. Based on these data, it can be seen that the cases of DV in Bantul Regency are relatively high. Therefore, this study attempts to determine the relationship between physical and psychological violence in dating with sleep duration of adolescents in Bantul Regency.

\section{Materials and Method}

This research takes the form of quantitative research using a cross sectional approach. Data were collected using purposive sampling technique, namely by determining special characteristics. The population in this study was 32,815 high school students (SMA) in Bantul Regency. The number of samples that met the inclusion and exclusion criteria were 314 students. The inclusion criteria for the sample were students aged 15-19 years and have dated or are currently in relationship. The exclusion criteria were students who did not want to be respondents and students who did not complete the questionnaire. The number of samples was determined using the calculation as follows:

$$
n=\frac{z^{2}{ }_{1-\alpha / 2} p(1-p) N}{d^{2}(N-1)+Z^{2}{ }_{1-}{ }_{12} p(1-p)}
$$

Note:

$\mathrm{N}=$ Minimum number of samples required

$Z=Z$ score based on the desired value of $\alpha$

$\alpha=$ Degree of confidence

$\mathrm{d}=$ fault tolerance

$\mathrm{p}=$ special proportion studied in the population

$1-p=q$, which is the proportion for the occurrence of an event

$Z_{1-\propto / 2} \quad=1, .96$

Thus:

$$
\begin{aligned}
& \mathrm{n}=\frac{(1.96) 2(0.29)(1-0.29) 32.815}{(0.05)^{2}(32.815-1)+(1.96)^{2}(0.29)(1-0.29)} \\
& \mathrm{n}=\frac{25.945}{82.79} \\
& \mathrm{n}=313.38
\end{aligned}
$$

The variables in this study were physical violence (severe $=\bar{X} \geq 2$, mild $=\bar{X}<2$ ), psychological violence (severe $=\bar{X} \geq 2$, mild $=\bar{X}<2$ ), and sleep duration. The data analysis technique used were univariate and bivariate analysis using chi-square test and calculated with SPSS software. 


\section{Results and Discussion}

\subsection{Results}

3.1.1. Characteristic of Respondents

The respondents of this study were all high school students in Bantul Regency. The frequency distribution of respondents' characteristics based on gender, age, class, and parental income is presented in Table 1 . Based on Table 1, it can be seen that the majority of respondents were female (76.8\%). Most respondents were 16 years old $(30.3 \%)$ and were in the tenth grade $(34.1 \%)$. A large number of respondents $(43 \%)$ were in the category of having parental income less than 1,750,000 IDR. A significant number of respondents experienced mild physical violence $(65.3 \%)$ and mild psychological violence $(55.4 \%)$. The majority of respondents had insufficient sleep duration as many as 251 (79.9\%).

Tabel 1. Characteristic of Respondents

\begin{tabular}{lcc}
\hline \multicolumn{1}{c}{ Variable } & $\mathbf{n}$ & $\%$ \\
\hline Gender & & \\
Male & 73 & 23.2 \\
Female & 241 & 76.8 \\
Age & & \\
15 & 77 & 24.5 \\
16 & 95 & 30.3 \\
17 & 81 & 25.8 \\
18 & 57 & 18.2 \\
19 & 4 & 1.3 \\
Class & & \\
$\quad$ X (10) & 107 & 34.1 \\
$\quad$ II (11) & 106 & 33.8 \\
$\quad$ XII [12] & 101 & 32.2 \\
Parents' Income & & \\
$\quad<1,750,500$ & 48 & 43.0 \\
1,750,500 & 135 & 15.3 \\
$\quad$ 1,750,500 & 131 & 41.7 \\
Physical Violence & & \\
$\quad$ Severe & 109 & 34.7 \\
$\quad$ Mild & 205 & 65.3 \\
Psychological Violence & & \\
$\quad$ Severe & 140 & 44.6 \\
$\quad$ Mild & 174 & 55.4 \\
Sleep Duration & & \\
$\quad$ Insufficient & 251 & 79.9 \\
$\quad$ Sufficient & 63 & 20.1 \\
$\quad$ & & \\
\hline
\end{tabular}

Table 2 shows that the most frequent acts of physical violence experienced by respondents were pushing or pulling roughly (16\%). In terms of psychological violence, bringing up the past was the highest case $(7 \%)$.

\subsubsection{Bivariate Analysis}

Based on Table 3, the results of the chi square test show that there is a relationship between physical violence in adolescents and sleep duration (PR $=1,165 ; \mathrm{Cl} 95 \%=1,050$ $1,293 ; p<0.05)$. More details can be seen on Table 3.

Table 2. Forms of Physical and Psychological Violence Experienced by Adolescents 


\begin{tabular}{lcc}
\hline \multicolumn{1}{c}{ Variable } & $\mathbf{n}$ & $\%$ \\
\hline Physical Violence & & \\
Hitting or punching & 67 & 7 \\
Hitting or slapping & 59 & 6 \\
Clawing & 71 & 8 \\
Twisting hands & 74 & 8 \\
Slamming & 74 & 8 \\
Pushing or pulling & 154 & 16 \\
Biting & 75 & 8 \\
Suffocating & 76 & 8 \\
Forcing to get off a vehicle & 98 & 10 \\
Hurting with hard objects & 73 & 8 \\
Tearing clothes off & 57 & 6 \\
Coercing to have sex without consent & 62 & 7 \\
Psychological Violence & & \\
Disdaining & 210 & 4 \\
Demanding to obey the partner & 273 & 6 \\
Getting angry if reprimanded & 238 & 5 \\
Demanding sex & 155 & 3 \\
Limiting the partner's social life & 301 & 6 \\
Keeping the partner from his/her friends & 263 & 6 \\
Scolding in front of others & 225 & 5 \\
Being stingy & 229 & 5 \\
Underestimating academic ability & 226 & 5 \\
Shouting & 224 & 5 \\
Being disrespectful & 278 & 6 \\
Invoking fear & 237 & 5 \\
Treating the partner like a fool & 221 & 5 \\
Being rough & 240 & 5 \\
Mocking appearance & 219 & 5 \\
Threatening & 222 & 5 \\
Bringing up the past & 308 & 7 \\
Insulting in front of others & 202 & 4 \\
Scaring the partner & 207 & 4 \\
Saying hurtful things & 256 & 5 \\
\hline
\end{tabular}

Table 3. Bivariate Analysis Results

\begin{tabular}{|c|c|c|c|c|c|c|c|c|}
\hline \multirow{3}{*}{ Variable } & \multicolumn{4}{|c|}{ Sleep Duration } & \multirow{2}{*}{\multicolumn{2}{|c|}{ Total }} & \multirow{3}{*}{$\begin{array}{c}\text { P- } \\
\text { Value }\end{array}$} & \multirow{3}{*}{$\begin{array}{c}\text { PR } \\
\text { (Cl 95\%) }\end{array}$} \\
\hline & \multicolumn{2}{|c|}{ Insufficient } & \multicolumn{2}{|c|}{ Sufficient } & & & & \\
\hline & $\mathbf{n}$ & $\%$ & $\mathbf{n}$ & $\%$ & $\mathbf{n}$ & $\%$ & & \\
\hline \multicolumn{9}{|c|}{ Physical Violence } \\
\hline Severe & 96 & 8.2 & 3 & 20.6 & 09 & 4.7 & \multirow{2}{*}{0.013} & 1.165 \\
\hline Mild & 155 & 1.8 & 0 & 79.4 & 05 & 5.3 & & $(1.050$ \\
\hline \multicolumn{9}{|c|}{ Psychological Violence } \\
\hline Severe & 116 & 6.2 & 4 & 38.1 & 40 & 4.6 & \multirow[t]{2}{*}{0.309} & 1.068 \\
\hline Mild & 135 & 3.8 & 9 & 61.9 & 74 & 5.4 & & $(0.957-1.192)$ \\
\hline
\end{tabular}

\subsection{Discussion}

The results of the study indicate that adolescents experienced sleep disorders due to the impact of Covid-19 pandemic. They have insufficient sleep duration because school activities are carried out online. In addition, an interview with 3 students regarding student activities during the pandemic via WhatsApp chat revealed that student often stayed up late during the Covid-19 pandemic which ultimately affected their sleep duration. These students stayed up late because they did schoolwork, chatted with friends, and watched movies.

According to the results of interviews with students who are victims of physical violence in dating, the injuries from physical violence affected their activities. The victims were 
traumatized because of the wound or bruise that were painful and caused scars on the victim's body. In addition, the injuries also disrupt the victims' sleep duration [27-28].

The results of this study suggest that adolescents who experienced severe physical violence were 1,165 times more likely to experience sleep duration disorders than those who do not experience physical violence and are statistically significant. According to a study, physical violence such as pinching on certain body parts and throwing keys very hard at the face caused injuries to certain body parts [14]. Several studies also mentioned the impact of physical violence on victims includes feeling sick, being injured or disabled, and death [15].

Based on the results of this study, psychological violence with sleep duration had no statistical relationship. However, it was found that psychological violence disrupted the sleep duration of adolescents. This shows that a number of students experienced psychological violence which results in the disruption of sleep duration. This is in line with the results of a previous study which reported that their DV respondents experienced fear, sadness, and depression to the point of unable to concentrate and sleep due to the traumatic events [16,2526]. The results of an interview with one of the respondents who experienced psychological violence revealed that the victim experienced psychological pressure and felt less confident, depressed, and burdened by the experience. In addition, they felt anxious and sad, resulting in insufficient sleep duration.

Insufficient sleep duration is one of the triggers of stress that can cause health problems [29-30]. People who experience health problems such as psychological problems and problems in the daily activities have insufficient sleep duration. Insufficient sleep duration can affect a person's mood, reduce alertness, and increase the risk of vehicle accident [17].

It is important to take account of sleep duration because insufficient sleep duration change the body [19-21]. Changes that often occur include weakened immune system, weight gain, coronary heart disease, and hypertension [22-24]. These diseases can also affect adolescents. A number of adolescents with hypertensive disorders have a habit of staying up late which induce an increase in blood pressure, causing hypertension [18].

\section{Conclusion}

Based on the results of the previous analysis and discussion, it can be concluded that there is a relationship between physical violence in dating and sleep duration. However, no relationship is found between psychological violence in dating and sleep duration. Teenagers are advised to be more selective and careful when dating in order to prevent dating violence. In addition, teenagers can take advantage of the PIK-R program in schools or visit the counseling teachers that can help them to solve their problems.

\section{Declaration}

Acknowledgments: We would like to thank Universitas Ahmad Dahlan for providing the funding of this research. We would also like to thank all the people who agreed to be the respondents for this research.

\section{References}

1. Stokes CM, Alonso J, Andrade LH, Atwoli L, Cardoso G, Chiu WT, Dinolova RV, Gureje O, Karam AN, Karam EG, Kessler RC, Chatterji S, King A, Lee S, Mneimneh Z, Oladeji BD, Petukhova M, Rapsey C, Sampson NA, Scott K, Street A, Viana MC, Williams MA, Bossarte RM; WHO World Mental Health Survey Collaborators. Pre-marital predictors of marital violence in the WHO World Mental Health (WMH) Surveys. Soc Psychiatry Psychiatr Epidemiol. 2020 Mar;55(3):393-405. doi: 10.1007/s00127-019-01703-z. Epub 2019 Apr 16. PMID: 30993376; PMCID: PMC7410347.

2. Joppa MC. Dating Violence in Adolescence: Implications for Girls' Sexual Health. J Pediatr Adolesc Gynecol. 2020 Aug;33(4):332-338. doi: 10.1016/j.jpag.2020.02.007. Epub 2020 Feb 19. PMID: 32087402.

3. Prakash R, Manthri S, Tayyaba S, Joy A, Raj SS, Singh D, et al. Effect of Physical Violence on Sexually Transmitted Infections and Treatment Seeking Behaviour Among Female Sex Workers in Thane District, Maharashtra, India. PLoS One. 2016;11(3):1-19. doi: https://doi.org/10.1371/journal.pone.0150347

4. Zahl-Olsen R, Gausel N, Zahl-Olsen A, Bertelsen TB, Haaland AT, Tilden T. Physical Couple and Family Violence Among Clients Seeking Therapy: Identifiers and Predictors. Front Psychol. 2019;10(December):1-11. doi: https://doi.org/10.3389/fpsyg.2019.02847

5. Miller E, Jones KA, McCauley HL. Updates on Adolescent Dating and Sexual Violence 
Prevention and Intervention. Curr Opin Pediatr. 2018 Aug;30(4):466-471. doi: 10.1097/MOP.0000000000000637. PMID: 29750769; PMCID: PMC6453661.

6. Sari DE, Rokhanawati D. The Correlation Between Age of First Dating and Sexual Behavior of Adolescents and Young Adults in Indonesia. J Heal Technol Assess Midwifery. 2018;1(1):238. doi: https://doi.org/10.31101/jhtam.441

7. Slakoff DC, Aujla W, PenzeyMoog E. The Role of Service Providers, Technology, and Mass Media When Home Isn't Safe for Intimate Partner Violence Victims: Best Practices and Recommendations in the Era of COVID-19 and Beyond. Arch Sex Behav. 2020 Nov;49(8):27792788. doi: 10.1007/s10508-020-01820-w. Epub 2020 Aug 25. PMID: 32844303; PMCID: PMC7447204.

8. Taquette SR, Monteiro DLM. Causes and consequences of adolescent dating violence: a systematic review. J Inj Violence Res. 2019 Jul;11(2):137-147. doi: 10.5249/jivr.v11i2.1061. Epub 2019 Jul 2. PMID: 31263089; PMCID: PMC6646825.

9. Cheng SY, Shen AC, Jonson-Reid M. Profiles of Teen Dating Violence and Association With Depression Among Chinese Teens. J Interpers Violence. 2020 May 13:886260520918573. doi: 10.1177/0886260520918573. Epub ahead of print. PMID: 32401158.

10. Lo K, Woo B, Wong M, Tam W. Subjective sleep quality, blood pressure, and hypertension: a meta-analysis. J Clin Hypertens (Greenwich). 2018 Mar;20(3):592-605. doi: 10.1111/jch.13220. Epub 2018 Feb 19. PMID: 29457339.

11. Mazza M, Marano G, Lai C, Janiri L, Sani G. Danger in danger: Interpersonal violence during COVID-19 quarantine. Psychiatry Res. 2020 Jul;289:113046. doi: 10.1016/j.psychres.2020.113046. Epub 2020 Apr 30. PMID: 32387794; PMCID: PMC7190494.

12. Hillis SD, Mercy JA, Saul JR. The enduring impact of violence against children. Psychol Health Med. 2017 Apr;22(4):393-405. doi: 10.1080/13548506.2016.1153679. Epub 2016 Mar 16. PMID: 26979496.

13. Namy S, Carlson C, O'Hara K, Nakuti J, Bukuluki P, Lwanyaaga J, Namakula S, Nanyunja B, Wainberg ML, Naker D, Michau L. Towards a feminist understanding of intersecting violence against women and children in the family. Soc Sci Med. 2017 Jul;184:40-48. doi: 10.1016/j.socscimed.2017.04.042. Epub 2017 Apr 27. PMID: 28501019; PMCID: PMC5737762.

14. O'Connor-Terry C, Burton D, Gowda T, Laing A, Chang JC. Challenges of Seeking Reproductive Health Care in People Experiencing Intimate Partner Violence. J Interpers Violence. 2020 Sep 24:886260520959627. doi: 10.1177/0886260520959627. Epub ahead of print. PMID: 32969311.

15. Kwon J, Park S. [Experiencing Coercive Control in Female Victims of Dating Violence]. J Korean Acad Nurs. 2019 Feb;49(1):46-58. Korean. doi: 10.4040/jkan.2019.49.1.46. PMID: 30837442.

16. Jacques T, Alves RA, Fadaei S, Barbosa F. Real-Time Psychophysiological and Writing Correlates of Expressive Writing. Exp Psychol. 2020 Jul;67(4):237-245. doi: 10.1027/16183169/a000495. PMID: 33111656.

17. Abdulah DM, Piro RS. Sleep disorders as primary and secondary factors in relation with daily functioning in medical students. Ann Saudi Med. 2018;38(1):57-64. doi: https://doi.org/10.5144/0256-4947.2018.537

18. Busch V, Altenburg TM, Harmsen IA, Chinapaw MJ. Interventions that stimulate healthy sleep in school-aged children: a systematic literature review. Eur J Public Health. 2017 Feb 1;27(1):53-65. doi: 10.1093/eurpub/ckw140. PMID: 28177474.

19. Malhi N, Oliffe JL, Bungay V, Kelly MT. Male Perpetration of Adolescent Dating Violence: A Scoping Review. Am J Mens Health. 2020 Sep-Oct;14(5):1557988320963600. doi: 10.1177/1557988320963600. PMID: 33045903 ; PMCID: PMC7557791.

20. Muñiz-Rivas M, Vera M, Povedano-Díaz A. Parental Style, Dating Violence and Gender. Int J Environ Res Public Health. 2019 Jul 30;16(15):2722. doi: 10.3390/ijerph16152722. PMID: 31366170; PMCID: PMC6695886.

21. Dosil M, Jaureguizar J, Bernaras E, Sbicigo JB. Teen Dating Violence, Sexism, and Resilience: A Multivariate Analysis. Int J Environ Res Public Health. 2020 Apr 13;17(8):2652. doi: 10.3390/ijerph17082652. PMID: 32294915; PMCID: PMC7215810.

22. Chisholm CA, Bullock L, Ferguson JEJ 2nd. Intimate partner violence and pregnancy: epidemiology and impact. Am J Obstet Gynecol. 2017 Aug;217(2):141-144. doi: 10.1016/j.ajog.2017.05.042. Epub 2017 May 25. PMID: 28551446.

23. Arenas-Carbellido C, Arias Astray A, Emery CR. Dating Violence Heterogeneity in University Couples. The Cases of Spain and South Korea. Soc Work Public Health. 2020 Jul 1;35(6):368379. doi: 10.1080/19371918.2020.1775747. Epub 2020 Jun 16. PMID: 32543330.

24. Khanhkham A, Williams RD Jr, Housman JM, Odum M. Sexual Dating Violence, School-Based 
Violence, and Risky Behaviors Among U.S. High School Students. J Community Health. 2020 Oct;45(5):932-942. doi: 10.1007/s10900-020-00811-1. PMID: 32198599.

25. Fernández-González L, Calvete E, Orue I. Adolescent Dating Violence Stability and Mutuality: A 4-Year Longitudinal Study. J Interpers Violence. 2020 May;35(9-10):2012-2032. doi: 10.1177/0886260517699953. Epub 2017 Apr 3. PMID: 29294700.

26. Kisa $\mathrm{S}$, Zeyneloğlu $\mathrm{S}$. Perceptions and predictors of dating violence among nursing and midwifery students. J Adv Nurs. 2019 Oct;75(10):2099-2109. doi: 10.1111/jan.13982. Epub 2019 Apr 5. PMID: 30791113.

27. Smith AU, Reidy D, Norris AE. Teen Dating Violence and Suicide Risk Among Bisexual Adolescents. J Adolesc Health. 2020 Nov;67(5):685-691. doi: 10.1016/j.jadohealth.2020.04.014. Epub 2020 Jun 19. PMID: 32571755.

28. Cohen JR, Shorey RC, Menon SV, Temple JR. Predicting Teen Dating Violence Perpetration. Pediatrics. 2018 Apr;141(4):e20172790. doi: 10.1542/peds.2017-2790. Epub 2018 Mar 12. PMID: 29531125; PMCID: PMC5869330.

29. Goodcase ET, Toews ML, Perez-Brena NJ, Faflick N. Dating violence: A cross-lag path model with pregnant and parenting adolescents. J Adolesc. 2020 Jun;81:1-6. doi: 10.1016/j.adolescence.2020.03.006. Epub 2020 Apr 1. PMID: 32247190.

30. Indrayani T, Palutturi S, Amiruddin R, Syafar M, Birawida AB, Widowati R. The illustration of depression tendency on female teenagers due to dating violence in integrated service centre for woman and child empowerment DKI Jakarta 2020. Enferm Clin. 2020 Oct;30 Suppl 6:92-96. English, Spanish. doi: 10.1016/j.enfcli.2020.06.021. PMID: 33040950. 